\title{
GASIFICATION OF WASTES IN A PILOT FLUIDIZED BED GASIFIER
}

\author{
M. Campoy*, A. Gómez-Barea, P. Ollero, S. Nilsson, D. Fuentes-Cano \\ Bioenergy Group. Chemical and Environmental Engineering Department. \\ Escuela Técnica Superior de Ingeniería (University of Seville) \\ Camino de los Descubrimientos s/n. 41092 Seville (Spain) \\ *Corresponding author: Tel.: +34 954 481391; Fax: +34 954 461775; E-mail: mcampoy@esi.us.es
}

\begin{abstract}
A technical assessment of gasification of various wastes in fluidized bed was made by conducting test in a $100 \mathrm{~kW}_{\text {th }}$ pilot plant. The reactor was operated under simulated autothermal and adiabatic conditions, thus allowing scaling-up the results to industrial units. Four feed stocks were tested: orujillo, meat and bone meal, dried sewage sludge and compost from municipal solid waste. The tests were made for each fuel by changing the air ratio (stoichiometric ratio), allowing characterization of the process in terms of gas composition, gas heating value, gasification efficiency, carbon conversion and tar content. Comparison of the results with those obtained with commercial wood pellets was made. The results show that orujillo and dried sewage sludge are a potentially fuel to be gasified if carbon conversion is increased. On the other hand, gasification of meat and bone meal was found to be a process with low efficiency, despite the fuel is fully converted in the bed. Municipal solid waste is a fuel difficult to gasify because the gasification process has low efficiency and generates a great amount of ash difficult to dispose. In order to increase carbon conversion in the reactor, co-gasification of orujillo or sewage sludge with meat and bone meal is considered a promising option.
\end{abstract}

Keywords: gasification, waste, fluidized bed, pilot plant.

\section{INTRODUCTION}

Due to the high price of the clean (woody) biomass, the interest of converting cheaper fuels (wastes and dirty residues) is increasing. However, waste fuels often contain considerable amounts of ash, nitrogen, chlorine and sulfur, increasing the complexity of the process and/or making necessary more extensive gas cleaning. [1] The benefits of the low price of waste should prevail over both extra costs of gas cleaning and operation difficulties (agglomeration and sintering) [2]

Gasification is a feasible technology for biomass and waste utilization with neutral $\mathrm{CO}_{2}$ emissions. Standalone air-blown bubbling fluidized bed gasifier (FBG) coupled to a compression-ignition engine is a simple and economical system for small-scale power production $\left(<0.5-3 \mathrm{MW}_{\mathrm{e}}\right)[3]$. This technology has higher efficiency than a Rankine power cycle, thus providing an attractive option for remote locations [4].

A few lab and pilot scale studies have been carried out in FBG using a variety of wastes $[5-10 \ldots]$. The results obtained in these works are useful for identification of promising fuels and characterization of off-gas quality. However, few of them were conducted in autothermal conditions, i.e., in conditions similar to that of air-blown directly-heated FBG. The reason is that most of the tests in literature were made by adjusting independently the temperature and the stoichiometric ratio (or equivalence ratio), meaning that the results can not be directly scaled up to large plants [11]. Independent variation of temperature and stoichiometric ratio (SR) is achievable only in small rigs, where the temperature can be controlled by an electrical oven around the vessel.

This is, however, neither technically nor economically feasible for large-scale FBG.

This work is focused on a technical assessment of FBG of four wastes: orujillo (a by-product from olive oil industry), meat and bone meal (MBM), dried sewage sludge (DSS) and compost of municipal solid waste (MSW). The tests were conducted in a $100 \mathrm{~kW}_{\text {th }}$ airblown FBG operating under autothermal conditions in order to achieve representative results which can represent the operation of industrial facilities [11].
The results were compared to commercial wood pellets to identify differences between waste and cleanwoody biomass gasification.

\section{EXPERIMENTAL}

\subsection{Material}

Wood pellets used as reference for comparison with wastes are cylindrical with $6 \mathrm{~mm}$ mean diameter and 5-10 $\mathrm{mm}$ length. MBM was pelletized due to the difficulty for feeding as received (as meals with $<1 \mathrm{~mm}$ diameter). The final MBM pellets used were cylindrical with $5 \mathrm{~mm}$ wide and 4-8 $\mathrm{mm}$ height. Orujillo and DSS were fed as received: spherical particles with 1.7 and $2.8 \mathrm{~mm}$ mean diameter, respectively. Finally, MSW was received as "soft" (low mechanical strength) cylindrical pellets of 8 $\mathrm{mm}$ diameter and 8-10 $\mathrm{mm}$ height.

Table I: Chemical characterization of wood pellets, orujillo, meat and bone meal (MBM), dried sewage sludge (DSS) and municipal solid waste (MSW)

\begin{tabular}{|l|c|c|c|c|c|}
\hline & WOOD & ORUJILLO & MBM & DSS & MSW \\
\hline \multicolumn{7}{|c|}{ As received (\%w/w) } \\
\hline $\begin{array}{l}\text { LHV } \\
(\mathrm{MJ} / \mathrm{kg})\end{array}$ & 17.1 & 15.8 & 19.8 & 11.2 & 8.6 \\
\hline Moisture & 6.3 & 8.7 & 6.9 & 8.6 & 14.3 \\
\hline Ash & 0.7 & 13.0 & 17.8 & 39.4 & 38.2 \\
\hline Volatile & 75.9 & 59.4 & 67.1 & 47.3 & 40.3 \\
\hline $\begin{array}{l}\text { Fixed } \\
\text { carbon }\end{array}$ & 17.2 & 19.0 & 8.5 & 4.7 & 7.3 \\
\hline \multicolumn{7}{|c|}{ Dry basis (\%w/w) } \\
\hline $\mathrm{C}$ & 49.5 & 46.4 & 45.0 & 30.9 & 28.6 \\
\hline $\mathrm{H}$ & 5.8 & 5.3 & 6.4 & 4.4 & 3.2 \\
\hline $\mathrm{N}$ & 2.0 & 1.8 & 7.5 & 4.8 & 1.8 \\
\hline $\mathrm{S}$ & 0.1 & 0.2 & 0.6 & 1.2 & 0.5 \\
\hline $\mathrm{O}$ & 41.9 & 32.1 & 21.6 & 15.6 & 21.4 \\
\hline
\end{tabular}

Chemical characterization of the wood and wastes used in this work is presented in Table I. As it is shown ash content in DSS and MSW is very high, while ash content in orujillo and MBM is medium. The 
characterization of majority components of these ashes has revealed high sodium/potassium content in orujillo, DSS and MSW [12-14]. This is a key parameter for agglomeration/sintering tendency in fluidized bed gasification [2].
Ofite, a subvolcanic rock, was used as inert bed material. Ofite is a silicate with formula $(\mathrm{Ca} \cdot \mathrm{Mg} \cdot \mathrm{Fe} \cdot \mathrm{Ti} \cdot \mathrm{Al})_{2} \mathrm{O}_{6}$. It has an average particle size of $750 \mu \mathrm{m}$ and a particle density of $2620 \mathrm{~kg} / \mathrm{m}^{3}$. The chemical characterization of ofite is given in [16].

Table II: Gasification results of the pilot plants tests (see abbreviation in the Nomenclature)

\begin{tabular}{|c|c|c|c|c|c|c|c|c|c|c|c|}
\hline \multirow{2}{*}{\multicolumn{5}{|c|}{ Test number }} & \multicolumn{3}{|c|}{ WOOD } & \multicolumn{4}{|c|}{ ORUJILLO } \\
\hline & & & & & 1 & 2 & 3 & 4 & 5 & 6 & 7 \\
\hline \multicolumn{12}{|c|}{ Operational conditions } \\
\hline \multicolumn{5}{|c|}{ Fuel flow rate, FFR $(\mathrm{kg} / \mathrm{h})$} & 17.9 & 14.1 & 11.9 & 15 & 12.9 & 10.2 & 8 \\
\hline \multicolumn{5}{|c|}{ Air flow rate, $\operatorname{AFR}\left(\mathrm{Nm}^{3} / \mathrm{h}\right)$} & 18 & 18 & 18 & 14 & 17 & 14 & 14 \\
\hline \multicolumn{5}{|c|}{ Bed Temperature, $\mathrm{T}_{\text {bed }}\left({ }^{\circ} \mathrm{C}\right)$} & 785 & 808 & 813 & 770 & 830 & 835 & 870 \\
\hline \multicolumn{5}{|c|}{ Stoichiometric ratio, SR } & 0.24 & 0.3 & 0.36 & 0.23 & 0.34 & 0.37 & 0.43 \\
\hline \multicolumn{12}{|c|}{ Gas composition (\%v/v, dry) } \\
\hline \multicolumn{5}{|l|}{$\mathrm{CO}$} & 17.8 & 17.5 & 15.9 & 10.8 & 9.7 & 9.3 & 7.5 \\
\hline \multicolumn{5}{|l|}{$\mathrm{H}_{2}$} & 13 & 10.9 & 8.5 & 12.7 & 11.0 & 10.3 & 8.7 \\
\hline \multicolumn{5}{|l|}{$\mathrm{CO}_{2}$} & 14.4 & 14.8 & 15 & 15.2 & 16.8 & 17.5 & 17.9 \\
\hline \multicolumn{5}{|l|}{$\mathrm{CH}_{4}$} & 5.9 & 5.1 & 4.9 & 6.7 & 5.4 & 4.9 & 4.0 \\
\hline & & & & asific: & ation per & formanc & & & & & \\
\hline \multicolumn{5}{|c|}{ Lower heating Value, LHV (MJ/ $\mathrm{Nm}^{3}$ dry) } & 5.8 & 5.2 & 4.7 & 5.1 & 4.4 & 4 & 3.3 \\
\hline \multicolumn{5}{|c|}{ Gas yield, $\mathrm{GY}\left(\mathrm{Nm}^{3}\right.$ dry $\mathrm{N}_{2}$ free/kg d.a.f. $)$} & 0.89 & 1.01 & 1.02 & 1.21 & 1.37 & 1.41 & 1.47 \\
\hline \multicolumn{5}{|c|}{ Cold gasification efficiency, CGE (\%) } & 54.8 & 59.5 & 58.8 & 54.6 & 59.6 & 59 & 53.2 \\
\hline \multicolumn{5}{|c|}{ Carbon conversion, $\mathrm{CC}(\%)$} & 89.4 & 93.2 & 94.8 & 69.6 & 87.6 & 92.6 & 94.3 \\
\hline \multicolumn{5}{|c|}{ Tar concentration, $\mathrm{C}_{\mathrm{tar}}\left(\mathrm{g} / \mathrm{Nm}^{3}\right.$ dry $)$} & 24.3 & 23.2 & 16.9 & 16.1 & 12.3 & 11.6 & 9.9 \\
\hline & \multicolumn{5}{|c|}{ MBM } & \multicolumn{4}{|c|}{ DSS } & \multicolumn{2}{|c|}{ MSW } \\
\hline Test number & 8 & 9 & 10 & 11 & 12 & 13 & 14 & 15 & 16 & 17 & 18 \\
\hline \multicolumn{12}{|c|}{ Operational conditions } \\
\hline FFR & 12 & 10.2 & 9.6 & 8.7 & 7.2 & 16 & 11.6 & 9.2 & 7.5 & 17.8 & 10.2 \\
\hline AFR & 14 & 14 & 14 & 14 & 14 & 15 & 11 & 11 & 11 & 12 & 10 \\
\hline $\mathrm{T}_{\text {bed }}$ & 808 & 832 & 843 & 850 & 857 & 790 & 807 & 815 & 838 & 770 & 810 \\
\hline SR & 0.25 & 0.29 & 0.31 & 0.35 & 0.42 & 0.3 & 0.34 & 0.42 & 0.52 & 0.34 & 0.42 \\
\hline \multicolumn{12}{|c|}{ Gas composition $(\% \mathrm{v} / \mathrm{v}$, dry) } \\
\hline $\mathrm{CO}$ & 10.9 & 7.8 & 6.5 & 6.1 & 5.9 & 9.9 & 8.3 & 7.3 & 5.4 & 12.4 & 11.5 \\
\hline $\mathrm{H}_{2}$ & 7.8 & 3.9 & 2 & 1.7 & 1.2 & 8.4 & 10.2 & 9.4 & 6.8 & 10.2 & 8.3 \\
\hline $\mathrm{CO}_{2}$ & 13.8 & 14.4 & 14.2 & 13.4 & 12.6 & 15.2 & 16.1 & 16.5 & 17.6 & 13.6 & 15.1 \\
\hline $\mathrm{CH}_{4}$ & 4.1 & 3.8 & 3.1 & 2.7 & 2 & 5.1 & 6.6 & 4.6 & 3.5 & 2.8 & 2.6 \\
\hline \multicolumn{12}{|c|}{ Gasification performance } \\
\hline LHV & 3.7 & 2.8 & 2.1 & 1.9 & 1.6 & 4 & 4.5 & 3.6 & 2.7 & 3.7 & 3.3 \\
\hline GY & 0.94 & 0.95 & 0.93 & 1.06 & 1.31 & 1.07 & 1.37 & 1.44 & 1.43 & 1.21 & 1.30 \\
\hline CGE & 30.5 & 25.3 & 20.2 & 20.1 & 20.4 & 46.2 & 62.4 & 57.8 & 48.6 & 47.2 & 53.1 \\
\hline $\mathrm{CC}$ & 98.8 & 99 & 99 & 99.1 & 99.3 & 88.9 & 66.1 & 85 & 92.1 & 69.7 & 88.9 \\
\hline $\mathrm{C}_{\mathrm{tar}}$ & 25.3 & n.d. & 19.5 & n.d. & 19 & n.d. & n.d. & 16.7 & 15.4 & 24.3 & 22.1 \\
\hline
\end{tabular}

\subsection{Facility}

Figure 1 shows the layout of the pilot plant. The rig has been described in detail in previous works $[11,16$, 17] therefore only a brief summary is presented here.

The reactor is a bubbling fluidized bed divided into two zones: the bed, with an internal diameter of $150 \mathrm{~mm}$ and height of $1.40 \mathrm{~m}$, and the freeboard, with an internal diameter of $250 \mathrm{~mm}$ and height of $2.15 \mathrm{~m}$. A $45 \mathrm{~kW}_{\mathrm{e}}$ electrical oven covers both the reactor and freeboard allowing adjustment of the heat supply during the gasification process. The hot air can be preheated up to $550{ }^{\circ} \mathrm{C}$ in a $7 \mathrm{~kW}_{\mathrm{e}}$ electrical heater before the windbox.

The gas leaving the freeboard section passes through two cyclones, in series, collecting entrained particles. The gas sampling point is located downstream of the cyclones. The sampling line is electrically heated to avoid the condensation of organic compounds within the probe.

The composition of the produced gas is measured continuously $\left(\mathrm{CO}, \mathrm{CO}_{2}, \mathrm{CH}_{4}, \mathrm{H}_{2}\right.$ and $\left.\mathrm{O}_{2}\right)$ by an online analyzer. Tars (using Tar Protocol [15]), light hydrocarbons, particles, moisture and other contaminants $\left(\mathrm{NH}_{3}, \mathrm{H}_{2} \mathrm{~S}\right.$ and $\left.\mathrm{HCl}\right)$ are sampled and measured discontinuously. $\mathrm{NH}_{3}$ was captured using a $5 \% \mathrm{H}_{2} \mathrm{SO}$ aqueous solution and analyzed by means of ultravioletvisible spectroscopy. Capture method for $\mathrm{H}_{2} \mathrm{~S}$ was absorption in a $5 \% \mathrm{CdSO}_{4}$ solution and its content was determined by iodinemetry. Finally, $\mathrm{HCl}$ was analysis by ionic chromatography after its caption in distilled water.

After leaving the analysis section, the product gas enters a post-combustion chamber, operating at temperatures of up to $900{ }^{\circ} \mathrm{C}$. To avoid tar condensation, the pipes between the gasifier and the combustion chamber are maintained at a sufficiently high temperature using heating elements and insulation blankets.

\subsection{Operating conditions}

All the tests were conducted using ofite as bed material and air as gasifying agent. The air inlet temperature was $400{ }^{\circ} \mathrm{C}$ (set to simulate inlet temperature that can be achieved by heat recovery from the product 
gas without tar condensation [11]).

Table II summarizes the operational conditions and results of the 18 experiments conducted. A set of tests using wood pellets as fuel was conducted as reference.

These tests were carried out to study the differences when using different wastes, at various stoichiometric air ratios (SR), defined as the mass ratio between the amount of air fed in and the amount of air required for stoichiometric combustion. The biomass flowrate is changed from one test to another, but, for a limited range of this parameter in a FBG, the system can be analyzed approximately by mean of SR, as the biomass flow rate is expected to have a minor influence on the results.

Depending on the waste nature, different SR ranges were studied, trying to achieve reasonable operation stability (without agglomeration and/or feeding blockage) and gasification performance (high gasification efficiency and carbon conversion with relatively low tar content).

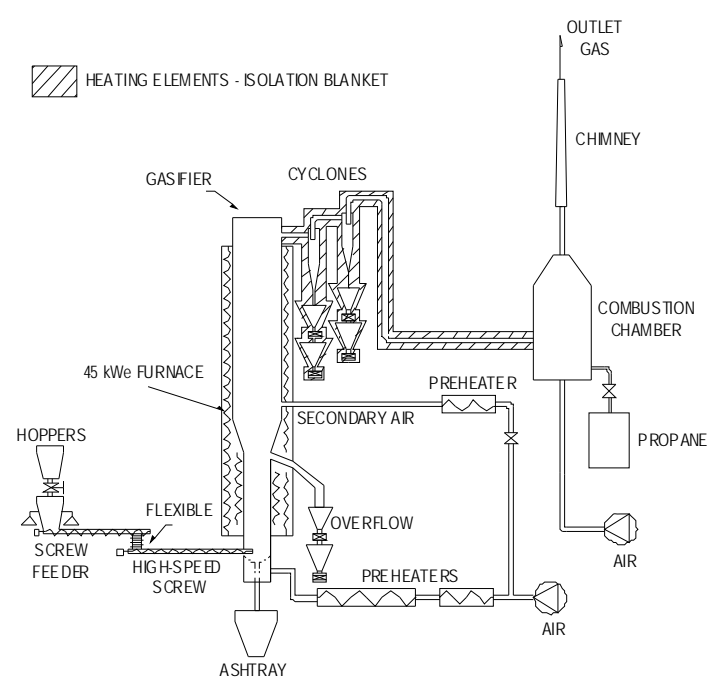

Figure 1: Pilot plant layout

\section{RESULTS AND DISCUSSION}

3.1 Operation stability

Firstly focus was done on solving technical problems (such as feedstock feeding and ash removal by overflow and drainage at the bottom) to enable long duration tests.

Orujillo and DSS could be fed easily without any further preparation, while for MBM and MSW had to be pelletized for proper feeding. This is a drawback for using MBM and MSW as fuel.

Gasification of MBM was easy to operate. Trials of up to 12 hours were achieved. Orujillo is a biomass presenting high sintering tendency. However, the use of an overflow in combination with bed material was enough for achieving tests of up to 10 hours. In contrast, operation with DSS and MSW was unsatisfactory (only 3-4 hours of gasification under stable conditions was achieved). The gasifier had to be shut down due to defluidization, caused by agglomeration of the material in the bed.

\subsection{Gasification performance}

The variables analyzed included process temperature, gas composition, gas yield, lower heating value of the gas, cold gasification efficiency, carbon conversion and tar content in the gas.

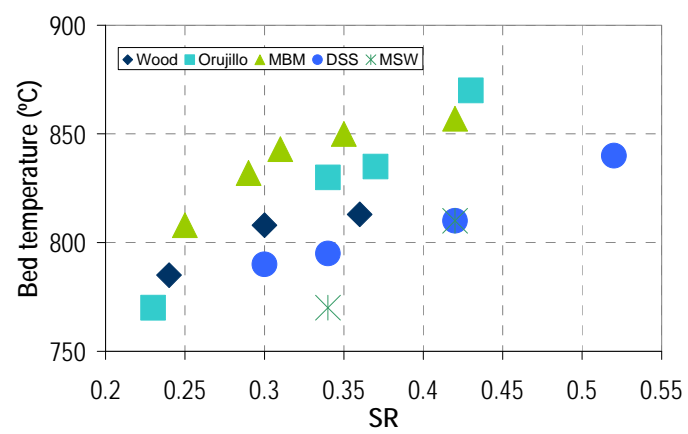

Figure 2: Bed temperature as a function of SR

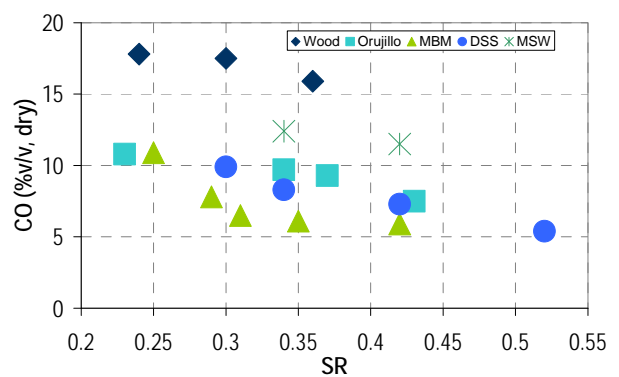

(a)

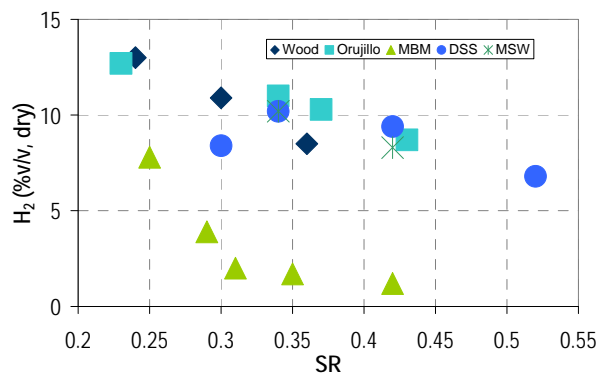

(b)

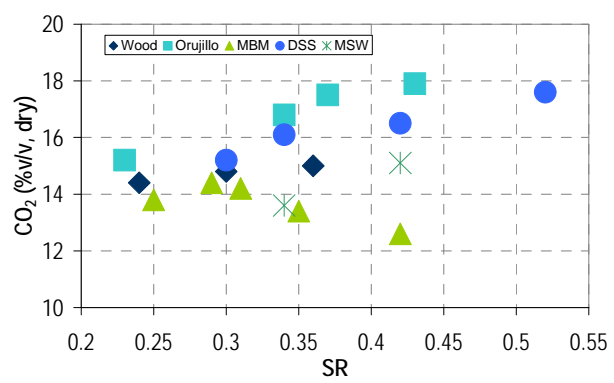

(c)

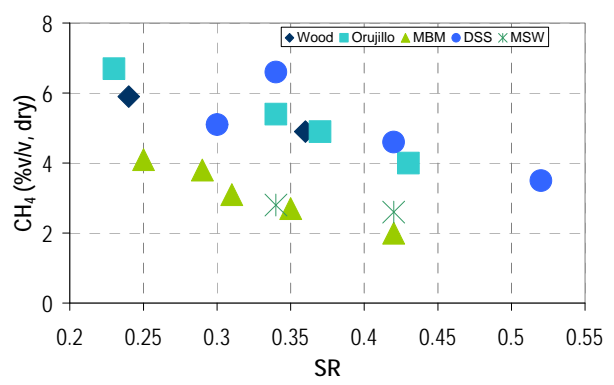

(d)

Figure 3: Gas composition of main species as a function of SR. (a) Carbon monoxide, (b) hydrogen, (c) carbon dioxide and (d) methane 
The effect of SR on the gasification temperature for the five biomasses tested is shown in Figure 2. As it was expected, the temperature increases when SR increases. It is noteworthy the very high temperature achieved with orujillo and MBM in comparison with DSS and MSW.

The effect of SR on the gas composition is given in Figure 3, expressed in \%v/v of dry gas. Figure 3(a) shows the carbon monoxide fraction in the gas. As expected, when increasing the SR, the CO the content decreased [18], this is related to more $\mathrm{CO}$ being combusted in the bed. Carbon monoxide content is lower when gasifying wastes compared to gasification of wood pellets.

Comparing the different wastes, MBM presents lower values of CO compared to MSW, but differences are not significant..

The hydrogen content is similar for all the fuels tested, varying between $13 \%$ (for low SR values) and $8 \%$ (high SR values) (see Figure 3(b)), except for MBM, which shows very low values when SR increases.

Figure 3(c) presents the $\mathrm{CO}_{2}$ content in the gas as a function of SR. For fuels tested, the $\mathrm{CO}_{2}$ increases when SR increases, excepting for MBM, which behavior is the opposite. Orujillo and DSS show the highest $\mathrm{CO}_{2}$ content in the gas, reaching values up to $18 \%$.

Finally, methane content is presented in Figure 3(d), where two different groups can be observed: one with high values (between 4-6\%) represented by wood, orujillo and DSS and another with low content (2-4\%), represented by MBM and MSW. This difference could be related to different devolatilization behavior, because almost no reaction of the methane formed during devolatilization occurs in the gasifier. Summarizing the results observed in the off-gas composition, it is remarkable the very low content of gaseous species different than nitrogen for MBM gasification. This is a consequence of the low oxygen content in the MBM, thus more air is necessary to reach typical SR values for gasification. Considering the high operation temperature when this fuel is gasified, the use of lower SR values (between 0.1 and 0.2 ) could be interesting, although there is a compromise, because for very low SR the tar content in the gas is high (as it will be shown later).

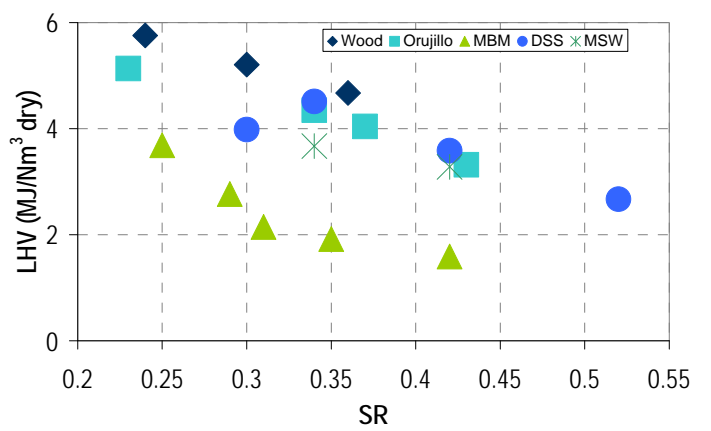

Figure 4: Lower heating value (LHV) of the off-gas as a function of SR.

Figure 4 presents the lower heating value (LHV) of the producer gas as a function of the SR, calculated including exclusively permanent (non-condensable) gaseous species. As it is well-known, if the SR is increased the LHV decreases due to oxidation of volatiles. The results show that orujillo and DSS generate a gas with LHV slightly lower than wood pellets, but the differences are not significant. On the other hand, as it was predicted previously, heating value of the gas produced from MBM is very low compared to the rest of the fuels tested, due to dilution of the gas with nitrogen.

Finally, MSW results are not clear, because there are not enough values for giving tendencies, but it seems that values are intermediate between MBM and wood pellets.

Figure 5 shows the effect of the SR on the gas yield (GY), expressed as $\mathrm{Nm}^{3}$ dry and nitrogen free per kilogram of biomass dry and ash free (d.a.f.).Orujillo and DSS gave high GY, while MBM and MSW present values close to those obtained with wood pellets. For all the biomasses tested, the GY increases when SR increases, being this an expected result.

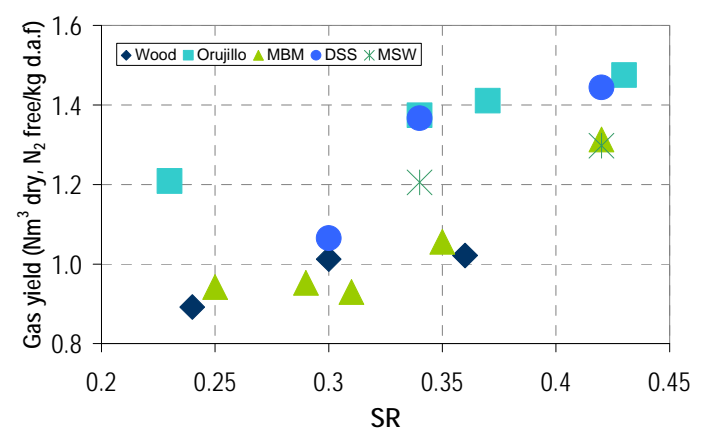

Figure 5: Gas yield as a function of SR.

Carbon conversion (CC) of the biomass (calculated as the difference between the carbon flow rate in the feed and cyclone ash, divided by the flow rate of carbon in the feed) as a function of SR for every biomass tested is shown in Figure 6. MBM shows the highest carbon conversion values in all the SR range tested (from 0.25 to 0.42 ) reaching values up to $99 \%$. These values are even higher than those obtained with wood pellets (CC up to 95\%). Carbon conversion was relatively low for orujillo, DSS and MSW (Figure 6). Only when SR is high (and therefore, the operation temperature) carbon conversion reaches values higher than $90 \%$.

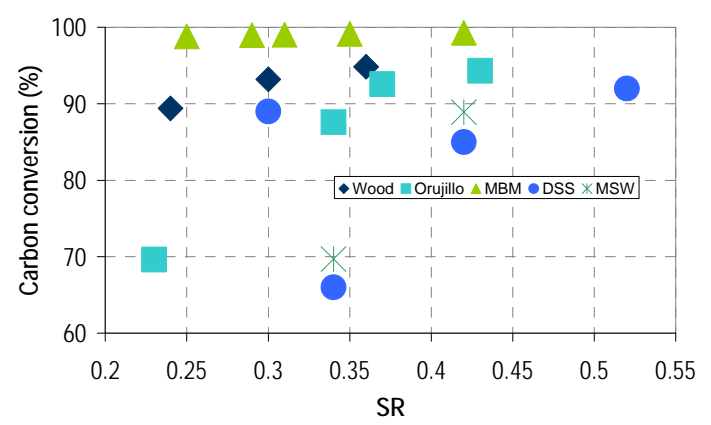

Figure 6: Carbon conversion as a function of SR.

Gasification efficiency, defined as the ratio of combustion heat of the produced gas calculated using the LHV defined above, to combustion heat of the biomass, is shown in Figure 7. Cold gasification efficiency (CGE) assumes a temperature of the product gases at $25^{\circ} \mathrm{C}$, so the sensitive heat of the gas is not taken into account. As it is presented in the figure, wood pellets, orujillo and DSS show very similar values, including a maximum for a SR value of about $0.3-0.35$. This maximum is the consequence of the increase of the GY and the decrease of the LHV with SR [16]. The highest value of CGE for 
the trials using MSW was found for $\mathrm{SR}=0.42$, but the efficiency was lower than those commented previously.

The gasification efficiency for MBM is very low (lower than 35\%), due to the low heating value of the gas.

Figure 7 also shows that CGE increases when SR values decreases. This indicates that lower SR could be interesting for reaching acceptable values for MBM gasification.

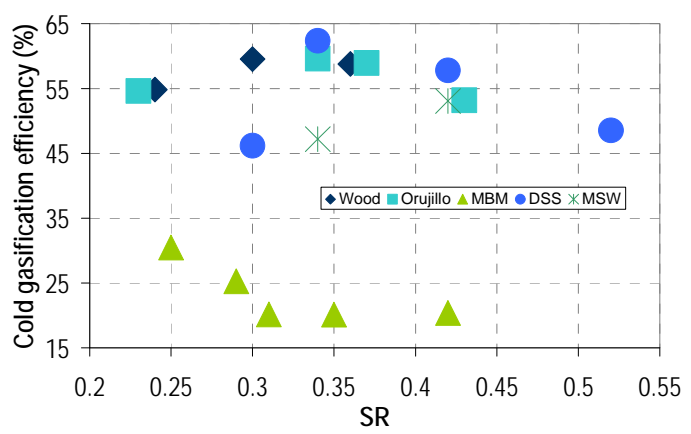

Figure 7: Cold gasification efficiency of the off-gas as a function of SR.

The gravimetric tar concentration in the off-gas as a function of the SR is presented in Figure 8. It is shown that the increase of the SR (bed temperature) involves a reduction of the tar concentration of up to $40 \%$ (in the case of orujillo). As it is shown, the higher values of tar content was found for MSW, wood pellets and MBM, while DSS and orujillo present lower values, probably due to the high content of alkalis and metals in their ashes [19].

Regarding contaminants compounds $\left(\mathrm{NH}_{3}, \mathrm{HCl}\right.$ and $\mathrm{H}_{2} \mathrm{~S}$ ) the following values were found for different fuels: wood pellets $\left(\mathrm{NH}_{3}\right.$ : 1000, $\left.\mathrm{HCl}: 200, \mathrm{H}_{2} \mathrm{~S}: 50 \mathrm{mg} / \mathrm{Nm}^{3}\right)$; DSS $\left(\mathrm{NH}_{3}: 2000, \mathrm{HCl}: 1000, \mathrm{H}_{2} \mathrm{~S}: 300 \mathrm{mg} / \mathrm{Nm}^{3}\right)$ and MSW ( $\mathrm{NH}_{3}$ : 1500, $\left.\mathrm{HCl}: 1500, \mathrm{H}_{2} \mathrm{~S}: 200 \mathrm{mg} / \mathrm{Nm}^{3}\right)$.

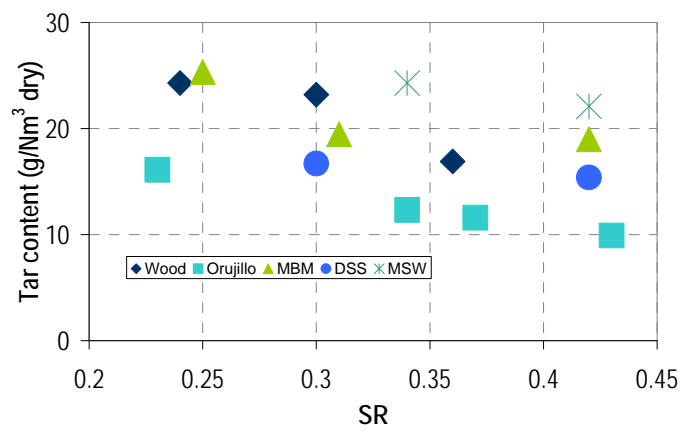

Figure 8: Gas gravimetric tar content as a function of SR.

\section{CONCLUSIONS}

Four wastes were gasified for their technical assessment in large scale fluidized bed units. MBM gasification yields a low heating value and efficiency due to low oxygen content in the fuel. In addition pelletization is needed, making the process unfeasible.

Olive oil residue (orujillo) generates a gas with good quality (similar to wood pellets), but the potassium content in the ash enhances sintering of the bed, making necessary to reduce temperature. Then low carbon conversion is reached due to the need of ash removal. Similar conclusions can be made for dried sewage sludge.

MSW residue has a negative cost and high availability but the gas produced has low heating value and high concentration of contaminants. In addition, the operation is difficult due to the strong tendency toward agglomeration.

\section{REFERENCES}

[1] S.V.B. van Paasen, M.K. Cieplik, N.P. Phokawat, Gasification of non-woody biomass. Report ECNC-06-032; Energy and Research Centre of the Netherlands (ECN): Petten, the Netherlands, 2006.

[2] M. Bartels, W. Lin, J. Nijenhuis, F. Kapteijn, J.R. van Ommen, Agglomeration in fluidized beds at high temperature: mechanisms, detection and prevention. Progress in Energy and Combustion Science (2008), 633-666.

[3] E. Kurkela, M. Nieminen, P. Simell, Development and commercialisation of biomass and waste gasification technologies from reliable and robust co-firing plants towards synthesis gas production and advanced power cycles. 2nd World Biomass Conference, Rome, Italy, May 10 - 14, 2004; Paper PA1.4.

[4] A.V. Bridgwater, A.J. Toft, J.G. Brammer, Technoeconomic comparison of power production by biomass fast pyrolysis with gasification and combustion. Renewable \& Sustainable Energy Reviews (2002), 6, 181-248.

[5] M. Aznar, A. E. González, J. J. Manya, J. L. Sánchez, M.B. Murillo, Understanding the effect of the transition period during the air gasification of dried sewage sludge in a fluidized bed reactor. Int. J. Chemical Reactor Engineering (2007), 5, A18.

[6] J.A. Conesa, A. Fullana, R. Font, Thermal decomposition of meat and bone meal. J. Anal. Appl. Pyrolysis (2003), 70, 619-630.

[7] A.T. Harris, S. A. Scott, J.S. Dennis, A.N. Hayhurst, J.F Davidson. The gasification of sewage sludge in bubbling fluidized beds. 17th International Fluidized Bed Combustion Conference, Jacksonville (Florida), USA, May 18 21, 2003; Paper 070

[8] J.J. Manya, J.L. Sánchez, A. Gonzalo, J. Arauzo, Air gasification of dried sewage sludge in a fluidized bed: effect of operating conditions and inbed use of alumina. Energy \& Fuels (2005), 19, 629-636.

[9] J.J. Manya, J.L. Sánchez, J. Ábrego, A. Gonzalo, J. Arauzo, Influence of gas residence time and air ratio on the air gasification of dried sewage sludge in a bubbling fluidised bed. Fuel (2006) 85, 20272033

[10] C.G. Soni, Z. Wang, A.K. Dalai, T. Pugsley, T. Fonstad, Hydrogen production via gasification of meat and bone meal in two-stage fixed bed reactor system. Fuel (2009), 88, 920-925.

[11] M. Campoy, A. Gomez-Barea, A. Villanueva, P. Ollero, Air-steam gasification under simulated autothermal and adiabatic conditions. Ind. Eng. Chem. Res. (2008), 47, 5957-5965

[12] S. Arvelakis, H. Gehrmann, M. Beckmann, E.G. Koukios, Agglomeration problems during fluidized bed gasification of olive-oil Residue: evaluation of 
fractionation and leaching as pretreatments. Fuel (2003), 82, 1261-1270

[13] M. Thamavithya, A. Duttab. An investigation of MSW gasification in a spout-fluid bed reactor, Fuel Processing Technology (2008) 89, 949-957

[14] R.S. Dahlin, W.W. Peng, M. Nelson, P. Vimalchand, G. Liu, Formation and prevention of agglomerated deposits during the gasification of high-sodium lignite. Energy \& Fuels (2006), 20, 2465-2470

[15] CEN/TS 15439. Biomass Gasification - Tar and Particles in Product Gases - Sampling and Analysis. Technical Specification, 2006.

[16] A. Gómez-Barea, R. Arjona, P. Ollero, Pilot plant gasification of olive stone: a technical assessment. Energy \& Fuels (2005), 19, 598-605.

[17] M. Campoy, A. Gomez-Barea, F. Vidal-Barrero, P. Ollero, Air-steam gasification of biomass in a fluidised bed: process optimisation by enriched air. Fuel Processing Technology (2009), 90, 677-685.

[18] I. Narváez, A. Orío, M.P. Aznar, J. Corella, Biomass gasification with air in an atmospheric bubbling fluidized bed. Effect of six operational variables on the quality of the produced raw gas. Ind. Eng. Chem. Res. (1996), 35, 2110-2120.

[19] D. Fytili, A. Zabaniotou, Utilization of sewage sludge in EU Applications of old and new methods - A review. Renewable and Sustainable Energy Reviews (2008), 12, 116-140

\section{NOMENCLATURE}

$\begin{array}{ll}\text { AFR: } & \text { Air flow rate }\left(\mathrm{Nm}^{3} / \mathrm{h}\right) \\ \text { CC: } & \text { Carbon conversion }(-) \\ \text { CGE: } & \text { Cold gasification efficiency (-) } \\ \mathrm{C}_{\text {tar: }}: & \text { Tar concentration }\left(\mathrm{g} / \mathrm{Nm}^{3} \text { dry) }\right. \\ \text { d.a.f.: } & \text { dry and ash free } \\ \text { DSS: } & \text { Dried sewage sludge } \\ \text { GY: } & \text { Gas yield }\left(\mathrm{Nm}^{3} \text { dry } \mathrm{N}_{2} \text { free } / \mathrm{kg} \text { d.a.f.) }\right. \\ \text { FBG: } & \text { Fluidized bed gasification } / \text { gasifier } \\ \text { FFR: } & \text { Fuel flow rate }(\mathrm{kg} / \mathrm{h}) \\ \text { LHV: } & \text { Lower heating value }\left(\mathrm{MJ} / \mathrm{Nm}^{3} \text { dry }\right) \\ \text { MBM: } & \text { Meat and bone meal } \\ \text { MSW: } & \text { Municipal solid waste } \\ \text { n.d.: } & \text { No data } \\ \text { SR: } & \text { Stoichiometric ratio }(-) \\ \mathrm{T}_{\text {bed }}: & \text { Bed temperature }\left({ }^{\circ} \mathrm{C}\right)\end{array}$

